\title{
A single Spanish version of Maternal and Paternal Postnatal Attachment Scales: validation and conceptual analysis
}

\author{
Anna Riera-Martín ${ }^{1}$, Antonio Oliver-Roig ${ }^{\text {Corresp.., }}{ }^{2}$, Ana Martínez-Pampliega ${ }^{1}$ ， Susana Cormenzana-Redondo ${ }^{1}$, \\ Violeta Clement-Carbonell $^{3}{ }^{\text {, }}$ Miguel Richart-Martínez $^{2}$ \\ 1 Department of Social and Developmental Psychology, University of Deusto, Bilbao, Spain \\ 2 Department of Nursing, University of Alicante, Alicante, Spain \\ 3 Department of Health Psychology, University of Alicante, Alicante, Spain \\ Corresponding Author: Antonio Oliver-Roig \\ Email address: antonio.oliver@ua.es
}

Background. Postnatal bonding constitutes a major process during the postpartum period and there is evidence that bonding difficulties have negative consequences for parents' mental health and the child's development. However, the conceptualization of postnatal bonding presents inconsistencies, as well as problems in having instruments that encompasses the father figure. The objective was to adapt the Maternal Postnatal Attachment Scale (MPAS) and the Paternal Postnatal Attachment Scale (PPAS) to Spanish, to evaluate its validity and reliability and to analyze the construct dimensionality of both questionnaires from a gender perspective.

Methods. Instrumental design. In 2016-2017, a sample of 571 mothers and 376 fathers, with children between six and eleven months of age, responded to the Spanish version of MPAS and PPAS, respectively. After the back-translation of the instrument, we empirically analyzed the internal consistency (Cronbach alpha, Composite Reliability) construct and concurrent validity (with regard to postpartum depression and dyadic adjustment). Additionally, we studied the instrument's content validity, using the Delphi methodology; and the differential analysis in both samples (mothers and fathers), examining the invariance.

Results. A short version of 15 items was obtained, common for mothers and fathers. The results of the Delphi methodology showed a 100\% inter-judge agreement, highlighting the absence of differences in the adequacy of the items as a function of the parents' gender. Confirmatory factor analysis showed a good fit of three original factors proposed by the authors. The global Cronbach alpha coefficients in the total sample were adequate (mothers, .70; fathers, .78); and Cronbach alpha of each dimension in the case of mothers was .50 (Quality of bonding), .55 (Absence of hostility) and .60 (Pleasure in interaction); in the case of fathers, it was respectively .54, .64, and .72. Composite Reliability (CR) of each dimension were: Quality of bonding, .74 in mothers and .80 in fathers; Absence of hostility, .93 in mothers and .94 in fathers; Pleasure in interaction, .83 in mothers and .90 in fathers. With regard to the analysis of group invariance, the results revealed empirical evidence of configural and metric invariance. Concurrent validity showed moderate negative correlations for postnatal depression (mothers, $r=-.41, p<.001$; fathers, $r=-.38, p<.001$ ), and positive correlations for dyadic adjustment (mothers, $r=.39, p<.001$; fathers, $r=.44, p<.001)$.

Discussion. A new version of the instrument was generated, with good psychometric properties, adequate for use both with mothers and with fathers. This scale helps evaluate postnatal maternal and paternal bonding, allowing to study it from within the family system, a necessary step forward to advance 
perinatal mental health. 
1 A single Spanish version of Maternal and Paternal Postnatal Attachment

\section{Scales: validation and conceptual analysis}

3 Anna Riera-Martín ${ }^{1}$, Antonio Oliver-Roig ${ }^{2}$, Ana Martínez-Pampliega ${ }^{1}$, Susana Cormenzana-

4 Redondo $^{1}$, Violeta Clement-Carbonell ${ }^{3}$, Miguel Richart-Martínez ${ }^{2}$

$5 \quad{ }^{1}$ Department of Social and Developmental Psychology, University of Deusto, Bilbao, Spain.

$6 \quad 2$ Department of Nursing, University of Alicante, Alicante. Spain.

$7 \quad{ }^{3}$ Department of Health Psychology, University of Alicante, Alicante, Spain.

9 Corresponding Author:

10 Antonio Oliver-Roig ${ }^{2}$

11 Email address: antonio.oliver@ua.es 


\section{ABSTRACT}

25 Background. Postnatal bonding constitutes a major process during the postpartum period and there is evidence that bonding difficulties have negative consequences for parents' mental health and the child's development. However, the conceptualization of postnatal bonding presents inconsistencies, as well as problems in having instruments that encompasses the father figure. The objective was to adapt the Maternal Postnatal Attachment Scale (MPAS) and the Paternal Postnatal Attachment Scale (PPAS) to Spanish, to evaluate its validity and reliability and to analyze the construct dimensionality of both questionnaires from a gender perspective.

Methods. Instrumental design. In 2016-2017, a sample of 571 mothers and 376 fathers, with children between six and eleven months of age, responded to the Spanish version of MPAS and PPAS, respectively. After the back-translation of the instrument, we empirically analyzed the internal consistency (Cronbach alpha, Composite Reliability) construct and concurrent validity (with regard to postpartum depression and dyadic adjustment). Additionally, we studied the instrument's content validity, using the Delphi methodology; and the differential analysis in both samples (mothers and fathers), examining the invariance.

Results. A short version of 15 items was obtained, common for mothers and fathers. The results of the Delphi methodology showed a 100\% inter-judge agreement, highlighting the absence of differences in the adequacy of the items as a function of the parents' gender. Confirmatory factor analysis showed a good fit of three original factors proposed by the authors. The global Cronbach alpha coefficients in the total sample were adequate (mothers, .70; fathers, .78); and (Absence of hostility) and .60 (Pleasure in interaction); in the case of fathers, it was respectively $.54, .64$, and .72. Composite Reliability (CR) of each dimension were: Quality of bonding, .74 in 
47 mothers and .80 in fathers; Absence of hostility, .93 in mothers and .94 in fathers; Pleasure in

48

49 interaction, .83 in mothers and .90 in fathers. With regard to the analysis of group invariance, the results revealed empirical evidence of configural and metric invariance. Concurrent validity showed moderate negative correlations for postnatal depression (mothers, $r=-.41, p<.001$; fathers, $r=-.38, p<.001$ ), and positive correlations for dyadic adjustment (mothers, $r=.39, p<$ .001 ; fathers, $r=.44, p<.001)$.

Discussion. A new version of the instrument was generated, with good psychometric properties, adequate for use both with mothers and with fathers. This scale helps evaluate postnatal maternal and paternal bonding, allowing to study it from within the family system, a necessary step forward to advance perinatal mental health.

\section{INTRODUCTION}

During the first years of life, newborns depend for their survival and development on their caregivers (Bowlby, 1969), who will provide the child's environmental context (De Cock et al., 2016). During this period, the parent-child relationship is crucial for the child's biological, cognitive, emotional, and social development (Belsky \& Fearon, 2002; Feldman, 2007). One of the most important processes in the postpartum period is the postnatal bonding between the parents and the baby (Brockington, 2004, 2011).

In the current state of scientific literature, the conceptualization of postnatal bonding presents inconsistencies, both linguistic and epistemological, across authors and disciplines, generating confusion and disagreement in practice (Bicking Kinsey \& Hupcey, 2013).

Linguistically, inconsistencies in the use and meaning of postnatal bonding are due to confusing the term with attachment, bonding and attachment being used interchangeably. Nonetheless, 
different authors have specifically differentiated the terms (Altaweli \& Roberts, 2010; Kennell \& McGrath, 2005; Taylor et al., 2005). For example, Taylor et al. (2005) comment that bonding is used to describe how the mother feels towards her baby; while attachment includes the behavior of the baby towards the mother. Epistemological inconsistencies are related to the directionality of the process, the domains that comprise it (affective, behavioral, and biological) and its temporality (Bicking Kinsey \& Hupcey, 2013).

Despite these inconsistencies, there is some consensus about identifying the emotional component of postnatal bonding in its different definitions (Brockington, Fraser \& Wilson, 2006; Condon \& Corkindale, 1998; Condon, Corkindale \& Boyce, 2008; Figueiredo et al., 2009; Taylor et al., 2005; van Bussel, Spitz \& Demyttenaere, 2010), in addition to being consistently operationalized by measuring instruments (Bicking Kinsey \& Hupcey, 2013). Therefore, according to the above, bonding is the term adopted in this study, meaning the unique emotional tie established between parents and their baby in early childhood.

Insights from studies on the negative consequences of postnatal bonding disorders both for the infant and for the parents highlight the importance of this concept. First, concerning the consequences for the infant, some studies relate low postnatal bonding quality with complications in the child's socioemotional development, increased parental perception of the infant's difficult temperament (De Cock et al., 2016; Mason, Briggs \& Silver, 2011), problems in the development of executive functions (De Cock et al., 2017), and externalizing behavior difficulties at 18 months of age (Hairston et al., 2011). Secondly, as to the consequences for parents, it was found that low-quality bonding predicts greater parental stress (De Cock et al., 2017; Mason, Briggs \& Silver, 2011), higher anxiety levels, less perception of the partner's support (De Cock et al., 2016), a negative effect on parenting skills and feelings of parental 
93 adaptation (Müller, 1994; Sidiqqui \& Hägglöf, 2000), as well as poorer quality of parent-child

94 interactions, for example, maternal response to the baby's signals (Hornstein et al., 2006).

95 Due to the importance of bonding and the consequences it can have on the infant and the parents, 96 in recent years, specific instruments have been developed for professionals of nursing, 97 psychology, pediatrics, and primary care to detect and prevent problems in early bonding. Easy98 to-use instruments that do not need much time or require sophisticated infrastructure to evaluate 99 qualitative information are required (van Bussel, Spitz \& Demyttenaere, 2010). In this sense, 100 self-reports are the most useful and applied evaluation strategies, and the following three are the 101 most extensively employed to evaluate early emotional bonding between the mother and the 102 newborn: the Maternal Postnatal Attachment Scale (MPAS: Condon \& Corkindale, 1998), the 103 Postpartum Bonding Questionnaire (PBQ: Brockington et al., 2001) and the Mother-to-Infant 104 Bonding Scale (MIBS: Taylor et al., 2005). These three instruments provide a reliable and valid 105 indication of the early emotional bond between a mother and her newborn infant (van Bussel, 106 Spitz \& Demyttenaere, 2010).

107 Although mother-infant bonding has received much attention over the last decade, the study of 108 the father's role in the context of early relations is still little addressed in research, despite studies 109 that have determined its great impact on the infant's development (De Cock et al., 2017; De Cock 110 et al., 2016; Ramchandani et al., 2013; Sarkadi et al., 2008). For example, Scism and Cobb 111 (2017) have shown that father-infant bonding in the postpartum period reduces cognitive delay, 112 promotes weight gain in premature infants, and improves the rate of breastfeeding. In addition, 113 incorporating fathers into the study of postnatal bonding, allows analyzing this concept from a 114 family system perspective. 
115 Only one of the above instruments, the MPAS, is based on a theoretical framework that 116 encompasses the father figure and provides an instrument adapted to fathers - the Paternal

117 Postnatal Attachment Scale (PPAS: Condon et al., 2008) - thereby incorporating a gender 118 perspective in the study of postnatal bonding. Additionally, it has adequate psychometric 119 characteristics, is easy to apply, and has been widely used in different studies (De Cock et al., 120 2017; De Cock et al., 2016).

121 These two scales, the MPAS and the PPAS, draw on the conceptualization of bonding as an 122 emotional state ("love") of the parents towards their baby. This emotional state leads to a series 123 of needs and dispositions directed towards the baby, which will determine paternal and maternal 124 behaviors (Condon, 1993; Condon \& Corkindale, 1998; Condon, Corkindale \& Boyce, 2008). 125 These dispositions or needs, according to Condon, Corkindale and Boyce (2008), differ in men 126 and women. In women, they focus on the pleasure of proximity, tolerance, the need for 127 gratification and protection, and the acquisition of knowledge (Condon \& Corkindale, 1998). In 128 men, the bonding indicators are patience and tolerance, pleasure in interaction, affection and 129 pride (Condon, Corkindale \& Boyce, 2008).

130 A review of the literature on the MPAS and the PPAS has identified several works related to the 131 adaptation of these scales to other countries. The MPAS has been adapted for use in Italy 132 (Scopesi et al., 2004), Belgium (van Bussel, Spitz \& Demyttenaere, 2010), Portugal (Nunes et 133 al., 2014), the United States (Feldstein et al., 2004), and Iran (Ghadery-Sefat et al., 2016). With 134 regard to the PPAS, it has been adapted for use in Portugal (Pires et al., 2014) and Turkey (Güleç $135 \&$ Kavlak, 2013). Various studies report appropriate values of reliability and validity but not all 136 the studies have analyzed their structural validity (van Bussel, Spitz \& Demyttenaere, 2010; 137 Feldstein et al., 2004; Ghadery-Sefat et al., 2016). Among those who have done so, 
138 inconsistencies have been found, as the three factor structure of the original scales could not be

139 replicated (Scopesi et al., 2004; Nunes et al., 2014; Pires et al., 2014). In this sense, in the Italian

140 version of the MPAS, six factors were obtained (Scopesi et al., 2004) and in the Portuguese

141 version of the two scales, two factors were obtained in each scale (Nunes et al., 2014; Pires et al.,

142 2014). The version of the PPAS adapted in Turkey is the only one to have managed to replicate

143 the original three-factor structure (Güleç \& Kavlak, 2013). All studies mentioned above were

144 performed on the general population. No studies have been found on clinical populations.

145 In short, contributing to progress in perinatal mental health requires validated instruments that 146 allow the early detection of problems in mother-infant and father-infant bonding. Currently, there

147 is no instrument validated in Spanish to assess postnatal bonding in both parents, making it 148 difficult to study bonding within the family system. As previously mentioned, only the MPAS 149 and the PPAS have both versions but, equally in this case, there is some discrepancy around the 150 instruments' structure.

151 Therefore, the present study had a twofold objective: to study the psychometric properties of the

152 Spanish version of the MPAS and the PPAS and, at the same time, to contribute to clarifying the 153 dimensions of the postnatal bonding construct in mothers and fathers.

\section{2. MATERIALS \& METHODS}

155 2.1. Design and Procedure

156 This instrumental study is part of a larger cohort study related to positive parenting (the PIPP 157 Project). The process of studying MPAS and PPAS was developed in three phases. In the first 158 phase, the scales were translated into Spanish. In the second phase, the data was collected. In the 159 third phase, the psychometric properties of the two scales were tested. 
161 The process of adaptation of the Spanish version of the MPAS and the PPAS began through a 162 process of translation-back-translation. Two bilingual translators made the Spanish translation, 163 and two different bilingual translators made the back-translation into English. The translators

164 worked independently. After completing this process, a committee of experts assessed the two 165 versions in English (original and back-translated), making sure that both questionnaires were 166 understandable and equivalent to the original. Finally, a pilot study was conducted with six men 167 and six women. The main problem reported by participants was the difficulty due to the 168 heterogeneous number of items' response options, and they proposed that all the items should 169 have the same number of response options. Taking into account these findings and the 170 recommendations of Condon (2015), in the final version, we decided to homogenize the number 171 of response options to five for all the items of both scales.

172 Phase 2: Data collection procedure

173 After recruiting the participants, we collected their contact details and requested them to 174 complete a battery of forms. Clinical data about childbirth and early puerperium were obtained 175 through the clinical history at postpartum discharge. At six months postpartum, a battery of 176 online questionnaires was sent, with a link containing a unique code for each participant that 177 allowed direct access to a self-reported form, which could be completed using a web browser.

178 Phase 3: Testing psychometric properties

179 The analysis of the distribution of items was performed by estimating for each score value the 180 mean $(\mathrm{M})$, standard deviation (SD), skewness index $(\mathrm{S})$, the correlation of each item with the 181 scale $(r)$, and the value of the Cronbach alpha coefficient if the item were eliminated $(\alpha-$ item).

182 In order to facilitate reading and interpreting the data, all the dimensions were coded in such a 183 way that a higher score indicated a higher intensity of the measured construct. Internal 
184 consistency was measured through Cronbach's alpha coefficient, with a value of .70 or higher

185 regarded as acceptable (Wu et al., 2011).

186 We applied structural covariance techniques to perform confirmatory factor analysis (CFA) of

187 the instrument's structure. We calculated the fit of our data to the measuring models using the

188 AMOS program and the maximum likelihood method (ML) (Arbucle, 2014). To analyze the

189 goodness of fit of the model, we used: the root mean square error of approximation (RMSEA)

190 and its confidence interval, considering values between .05 and .08 as acceptable, and less than

191.05 as very good; the goodness of fit index (GFI), and the comparative fit index (CFI),

192 considering values higher than .90 as adequate (Hair et al., 2006).

193 As we did not replicate the authors' original structure or the subsequent proposed validation

194 studies, we adopted a different approach, based on a study of the instrument's content validity

195 and a differential analysis of the two versions of the instrument. Firstly, we studied the relevance

196 of each item of the postnatal bonding construct using the Delphi methodology (Landeta, 1999).

197 For this purpose, we invited a total of six experts in the field to perform their assessment. They

198 agreed on the existence of a single version, common to both parents. Secondly, we performed

199 confirmatory factor analysis of this resultant single version. Thirdly, internal consistency was

200 measured using Cronbach's alpha coefficient for the global scale and for each subscale.

201 Additionally, the Composite Reliability (CR) was calculated in order to obtain another indicator

202 of the degree of internal consistency. This measure was calculated based on the standardized

203 lambda coefficients $(\gamma)$ and their respective measurement errors $(\delta)$ resulting from the

204 confirmatory factor analysis, with the recommended values being equal to or greater than .70.

205 Fourthly, we examined the invariance between the data from the application to mothers and

206 fathers. For this purpose, we carried out the steps indicated by the model developed by Little 
207 (1997), which establishes the need for the four types or models of invariance for a complex

208 analysis: configural, metric, strong, and strict invariance. We performed multi-group comparison

209 (for example, configural model vs. metric model). To interpret the results, we used the $\Delta C F I$

210 value. Finally, concurrent validity of the instrument was analyzed through Pearson correlations

$211(r)$ with the variables postnatal depression and quality of the couple relationship.

212 2.2. Participants

213 Initially, the sample consisted of 1,980 women and 1,721 men recruited at postpartum discharge

214 from the hospital. As inclusion criteria, all participants were parents of a full-term newborn baby, 215 with low or medium risk pregnancies and births (according to the classification of obstetric risk 216 of the Mother Care Program of local health council), who could speak and read Spanish without 217 difficulty. Participants whose contact details were erroneous (353 men and 470 women) were 218 excluded from the sample. Some participants decided to leave the study at five months 219 postpartum (55 men and 27 women). Hence, 1,313 men and 1,483 women were included in the 220 study, but only 571 women and 376 men completed the required questionnaires. Therefore, these 221 data indicate a response rate of $38.5 \%$ for mothers, and $28.6 \%$ for fathers (see Figure 1).

222 Mothers and fathers who participated in the study differed significantly from those who did not 223 participate regarding the following characteristics: they were older, primiparous, Spanish 224 nationality, higher educational level, and higher economic income. There were no significant 225 differences in their marital status, nor according to whether they were living together with their 226 partner.

227 ----Figure 1 about here----

228 Regarding the participants' characteristics, the women's mean age was 34.13 years, and the men's 229 was 35.98 years. Most of the participants were of Spanish nationality, married and living with 
230 their partner, had university studies, and their income was between 12,000 and 30,000 euros a

231 year (see Table 1).

232 ----Table 1 about here----

233 2.3. Instruments

234 Postnatal bonding. Maternal Postnatal Attachment Scale (Condon, \& Corkindale, 1998), and

235 Paternal Postnatal Attachment Scale (Condon, Corkindale \& Boyce, 2008). The MPAS and 236 PPAS were used to evaluate postnatal parental bonding.

237 The MPAS is divided into three factors (Condon \& Corkindale, 1998; Condon, 2015). The first

238 factor is the Quality of bonding (formerly called Quality of attachment) (9 items), which consists

239 of confidence and satisfaction in interaction with the infant (e.g., "When I am with the baby and

240 other people are present, I feel proud of the baby"). The second factor is the Absence of hostility

241 (5 items), defined as the absence of hostile feelings or anger towards the infant (e.g., "When I am

242 caring for the baby, I get feelings of annoyance or irritation"). The third factor is Pleasure in

243 interaction (5 items), defined as the desire for physical closeness and joy in interaction with the

244 baby (e.g., "When I am not with the baby, I find myself thinking about the baby”). The

245 psychometric properties of the original version of the scale have shown adequate internal

246 consistency of the global scale (Cronbach alpha of .78) (Condon \& Corkindale, 1998). However,

247 the structure of the factors has not yet been adequately established (Condon \& Corkindale,

248 1998). Concerning concurrent validity, only the global score was considered, evaluated by means

249 of the variables depression and anxiety, among others. The results obtained were consistent with

250 the bonding literature (Condon \& Corkindale, 1998), i.e. the higher scores in postnatal bonding,

251 the lower scores in depression and anxiety. 
252 The PPAS is divided into three factors (Condon, Corkindale \& Boyce, 2008). The first factor is

253 Patience and tolerance ( 8 items), defined as the absence of irritability and other negative affect

254 towards the baby, such as the lack of resentment about the impact of paternity (e.g., "When I'm

255 looking after my baby, I feel sad, frustrated or irritated”). The second factor is Pleasure in

256 interaction (7 items), consisting of feelings of pleasure, satisfaction, and competence in real

257 interactions with the baby (e.g., "When I am with my baby, I feel...”). The third factor is

258 Affection and pride (4 items), representing more stable and lasting feelings and cognitions

259 towards the baby, including a sense of ownership (my baby), a sense of pride, and feelings of

260 affection towards the baby (e.g., "In the last three months, I felt I have had no time for myself or

261 to do things that I'm interested in"). The results indicated adequate values of internal

262 consistency in the global scale (.81) and the different subscales $(.75, .71$, and .71) (Condon,

263 Corkindale \& Boyce, 2008). Regarding concurrent validity, the results were as expected

264 according to the theory (Condon, Corkindale \& Boyce, 2008).

265 Both scales have 19 items, with two to five response options. However, some versions of the

266 instrument have five response options (Scopesi et al., 2004), ranging from 1 (low bonding) to 5

267 (high bonding), in order to ensure equal weighting of the items. In this study, we decided to use

268 this response scale, as mentioned in the section on translation and adaptation procedures.

269 Postnatal depression. Edinburgh Postnatal Depression Scale (EPDS: Cox, Holden, \& Sagovsky,

270 1987). In this study, we used the adapted version of Garcia-Esteve et al. (2003), which maintains

271 the structure of the original scale. This is a self-administered 10-item scale designed to evaluate

272 the presence of postpartum depression (e.g., "I could laugh and see the funny side of things").

273 Each item is rated on a 4-point scale (0-3), with a total score ranging from 0 to 30 , where higher

274 scores indicate greater presence of symptoms of postpartum depression. In this version, the 
275 identified cut-off point was 10-11 for the presence of postpartum depression (Garcia-Esteve et

276 al., 2003). Maroto, García, and Fernández (2005) presented the psychometric characteristics of

277 the Spanish version, and determined high internal consistency (Cronbach alpha of .79) and a

278 two-factor structure (Sadness and Anxiety).

279 Dyadic adjustment. Dyadic Adjustment Scale (DAS: Spanier, 1976). This variable was studied 280 through the Spanish version of Santos-Iglesias, Vallejo-Medina, and Sierra (2009). This version 281 is a self-administered 13-item scale designed to assess the quality of the couple's relationship 282 (e.g., “How often do you and your partner argue?”). Each item has five or six response options. 283 Its structure is made up of three factors: Satisfaction, Consensus, and Cohesion. The 284 psychometric properties of the scale have shown an overall internal consistency of .83, and .73, 285.70 , and .63 for the subscales of Consensus, Satisfaction, and Cohesion, respectively, as well as 286 adequate validity (Santos-Iglesias, Vallejo-Medina \& Sierra, 2009).

287 2.4. Ethical Considerations

288 The study was approved by the Ethical Committee of Clinical Research of the General Direction 289 of Public Health and Higher Center of Research in Public Health (CEIC-DSGSP/CSISP), 290 attached to the Health Council of the Valencian Community. The participants were informed of 291 the study and gave informed consent by signing a written document. Only the members of the 292 research team had access to personal data, which were replaced in the forms and databases by an 293 alphanumeric code for each participant, in order to guarantee confidentiality.

\section{3. RESULTS}

3.1. Reliability and Validity of the MPAS and the PPAS

Analysis of the distribution of the items of the MPAS (Table 2) and PPAS (Table 3) showed a high and negative skewness, reflecting a grouping response tendency toward the highest scores. 
298 In this sense, high scores are indicators of higher postnatal bonding. In the case of the mothers'

299 version, we observed an exception, with Item 17 showing positive skewness. In both

300 instruments, items with a kurtosis index equal to or greater than 2 indicated a high homogeneity

301 in the responses (George \& Mallery, 2010).

302 ---- Table 2 and table 3 about here----

303 The correlation of the items for both instruments was low-moderate (MPAS: between .215 and 304 .487, and PPAS between .107 and .642). The MPAS obtained internal consistency, assessed by

305 Cronbach's alpha, of .75 on the global scale; and of .63, .56, and .61 in the subscales of Quality 306 of bonding, Absence of hostility, and Pleasure in interaction, respectively. The PPAS obtained 307 internal consistency of .83 for the global scale, and of $.78, .62$, and .58 for the subscales of 308 Patience and tolerance, Pleasure in interaction, and Affection and pride, respectively. The 309 analyses showed no improvement of these reliability indices upon deleting any of the items from 310 the subscales.

311 The KMO index and Bartlett's sphericity test indicated that the data matrix was factorizable for

312 both instruments, so we proceeded to perform confirmatory factor analysis.

313 First, we verified the three-factor structure of the original model of the original version of the 314 MPAS (Condon \& Corkindale, 1998) and PPAS (Condon, Corkindale \& Boyce, 2008). The 315 results did not show adequate goodness of fit in either instrument. Although RMSEA and GFI 316 indices had acceptable values, the CFI index did not reach the recommended cut-off value.

317 Secondly, we verified the two-factor structure factor of the Portuguese version of the MPAS 318 (Nunes et al., 2014) and the PPAS (Pires et al., 2014), made up of 14 and 16 items, respectively. 319 As in the former case, the CFI index did not reach the necessary cut-off point for the goodness of 320 fit of the model to be considered adequate. 
321 Lastly, a new analysis was performed, only in the case of the MPAS, to confirm the six-factor

322 structure of the Italian version (Scopesi et al., 2004). However, again, the required values for the

323 entire set of indices measured were not achieved (see table 4).

324 ---- Table 4 about here----

325 3.2. Reliability and Validity of a single version for mothers and fathers

326 Due to the inadequacy of the prior confirmatory analyses, a panel of experts met to determine, on 327 the one hand, the degree of relevance of the items of the two scales; on the other hand, the 328 existence of differences between maternal and paternal bonding. Six experts participated in the 329 study, all of them researchers in the concept of postnatal bonding, four of whom also had a 330 clinical profile, with a long history of working with infants and families. The results showed a $331100 \%$ inter-judge agreement, highlighting the absence of differences in the adequacy of the items 332 as a function of the parents' gender. Therefore, we continued the analysis, using a common 333 version for mothers and fathers, called Postnatal Bonding Scale (PBS), which was made up of 15 334 items, after deleting the unshared items (items 5, 6, 8, and 17 of the mother's version, and items $6,8,9$, and 15 of the father's version).

336 Firstly, a confirmatory analysis was performed of the new version, using as reference the original 337 three-factor version of the MPAS, the first instrument developed by the authors (see Figure 2, for 338 mothers; figure 3, for fathers). The results showed an adequate fit (Table 4), as their indexes 339 reached the recommended values (in mothers: $\mathrm{GFI}=.96, \mathrm{CFI}=.91, \mathrm{RMSEA}=.049$; in fathers: $340 \mathrm{GFI}=.93, \mathrm{CFI}=.90, \mathrm{RMSEA}=.060)$.

341 ---- Figure 2 and Figure 3 about here----

342 The data obtained showed how the correlation coefficients between the three subscales took high 343 and significant values, showing a high interrelation between the components of the instrument: 
344 Quality of bonding and Absence of hostility (Mothers: $r=.81, p<.001$; Fathers: $r=.84, p<.001$ )

345 Quality of bonding and Pleasure in interaction (Mothers: $r=.83, p<.001$; Fathers: $r=.73, p<$ 346.001 ), and Absence of hostility and Pleasure in interaction (Mothers: $r=.66, p<.001$; Fathers: $r=$ $347.53, \mathrm{p}<.001)$. All the standardized coefficients were statistically significant and obtained a value 348 near or greater than .40, with the exception of Items $4(\lambda=.30), 9(\lambda=.26)$, and $19(\lambda=.32)$ in 349 the case of mothers; and of Item $4(\lambda=.20)$ in the case of fathers. Lastly, the internal consistency 350 index, analyzed through Cronbach's alpha coefficient, was .70 for mothers and .78 for fathers.

351 Regarding the subscales, the strategies used were the Cronbach's alpha coefficient and the CR.

352 The results obtained were as follows: in the case of the mothers $\alpha=.50$ and $\mathrm{CR}=.74$ for Quality 353 of bonding; $\alpha=.55$ and $\mathrm{CR}=.93$ for Absence of hostility, and $\alpha=.60$ and $\mathrm{CR}=.83$ for Pleasure in 354 interaction. In the case of fathers, results were respectively: $\alpha=.54$ and $\mathrm{CR}=.80, \alpha=.64$ and $\mathrm{CR}=$ 355.94 finally $\alpha=.72$ and $\mathrm{CR}=.90$. With regard to the analysis of group invariance (see Table 5), the 356 results revealed empirical evidence of configural (Model 1) and metric invariance (Model 2) 357 when comparing the responses of mothers and fathers. The overall results indicated the viability 358 of constraining the factor loading to be the same across the groups. However, the CFI difference 359 between Model 3 and Model 2 was higher than .001 , which indicated that invariance of the 360 intercepts was not complete across the two groups. The lack of invariance at this level does not 361 permit the analysis of strict invariance, so we could not conduct analysis of differences in the 362 latent or observed variables.

363 ---- Table 5 about here----

364 In the analysis of concurrent validity, moderate negative correlations were found for the EPDS 365 (in mothers, $r=-.41, p<.001$; and fathers, $r=-.38, p<.001$ ), and positive correlations for the 366 DAS (in mothers, $r=.39, p<.001$; and in fathers, $r=.44, p<.001$ ). Thus, higher scores in 
367 postnatal bonding were associated with lower scores in depressive symptomatology and higher

368 quality of the couple's relationship.

\section{4. DISCUSSION}

370 The objective of this study was to examine the psychometric properties of the Spanish version of 371 the MPAS and the PPAS through the analysis of internal consistency, construct and concurrent

372 validity, and thereby, to contribute to clarifying the dimensions of the construct of postnatal

373 bonding in mothers and fathers. The results of the study were obtained from a 15-item brief

374 version, common for mothers and fathers, called Postnatal Bonding Scale (PBS), which showed 375 a good fit to the original three-factor structure proposed by Condon and Corkindale (1998):

376 seven items belonged to the Quality of bonding dimension, four items to the Absence of hostility

377 dimension, and four items to the Pleasure in interaction dimension. Worthy of note, to maintain

378 the coherence of the study's theoretical framework and avoid further terminological ambiguity,

379 the term 'attachment' (in the original scale) was changed for 'bonding'. This latter term 380 corresponds to the construct evaluated by the instrument.

381 The results obtained in the sample used in this study did not confirm the original three-factor 382 solution of the MPAS (Condon \& Corkindale, 1998) or the PPAS (Condon, Corkindale \& 383 Boyce, 2008), or the alternative models of the Italian version of the MPAS (Scopesi et al., 2004), 384 or the Portuguese version of the two scales (Nunes et al., 2014; Pires et al., 2014). Therefore, 385 none of the evidence found in previous research on the structure of the scale was observed in this 386 study. These results could indicate problems in the initial structure of the scales, due to the 387 construction process: unstructured interviews with small samples (10 women in the case of the 388 MPAS, and 15 men in the case of the PPAS), the reduction from 31 to 19 items in both scales 
389 due to statistical decisions (Condon \& Corkindale, 1998; Condon, Corkindale \& Boyce, 2008),

390 and the heterogeneity in the response option alternatives.

391 Due to the lack of adequacy of previous confirmatory analyses, we considered the option of 392 using a single version for men and women, using the 15 items common to both scales. This 393 decision was initially proposed for theoretical reasons, and we subsequently confirmed its 394 psychometric properties.

395 The theoretical reasons that justified this proposal are as follow. First, most psychological constructs are evaluated using instruments common to men and women, despite recognized gender differences (e.g., emotional intelligence; Gartzia et al., 2012). In this sense, it is understood that the essence of the concept is the same, although there may be differences in its expression. Therefore, in this way, the postnatal bonding construct could be assessed using a common instrument for men and women. Secondly, to separate an instrument by sex variable men and women- is made difficult due to the gender identity variable, since this variable may be 402 more important than sex to explain the differences between men and women (Gartzia et al.,2012). Thus, having a postnatal bonding's instrument which is suitable both for men and 404 women, avoids the possibility of mistaking due to disregarding the distinction between sex and gender identity. Thirdly, disposing of common tools made up of the same items permits direct comparison between the bonding of men and women. In this sense, De Cock et al. (2016) defended the need for an instrument that evaluates prenatal and postnatal bonding conjointly in order to advance in parental bonding research. Likewise, this same argument can be used for postnatal bonding in men and women. Fourthly, different studies have used the same instrument of postnatal bonding in men and women (Edhborg et al., 2005; Hall et al., 2015; Salian \& Shah, 
411 2017), despite the fact that no studies have been found that specify the adaptation of this 412 instrument to fathers.

413 In addition, it was considered necessary to use a panel of experts to obtain more evidence on the 414 degree of relevance of the items both in men and women. The experts fully agreed that there 415 were no differences in the degree of relevance of the items for men and women.

416 Therefore, evaluating these arguments, we considered that, at a theoretical level, a common 417 instrument for men and women was adequate, and this was supported empirically.

418 We confirmed the three-factor structure of the original MPAS, the first instrument created by the 419 authors (Condon \& Corkindale, 1998), showing adequate fit index values. The majority of the 420 standardized coefficients were statistically significant, with the exception of four items (Items 4, 4219 , and 19 in the case of mothers, and Item 4 in the case of fathers). It will be necessary to analyze 422 the functioning of these items in future studies.

423 The results of the global Cronbach alpha coefficients in the total sample were adequate (.70 for 424 mothers and .78 for fathers) and similar to the values found in the original versions (Condon \& 425 Corkindale, 1998; Condon, Corkindale \& Boyce, 2008) and in the Italian version (Scopesi et al., 426 2004). However, the Cronbach alpha for the subscales showed lower values, above all in the case 427 of mothers. In this case, we could not compare it with the original version or the Italian version, 428 because these findings were not indicated. On the other hand, the Portuguese version (Nunes et 429 al., 2014) and the Belgian version (van Bussel, Spitz \& Demyttenaere, 2010) of the MPAS also 430 reported values similar to those obtained in the internal consistency of the subscales.

431 Due to the limitations of this method for reliability analysis (Domínguez-Lara \& Merino-Soto, 432 2015; Lozano, García-Cueto \& Muñiz, 2008), the CR was used. It is based on a structural 433 equation modeling approach and represents a more accurate alternative for calculating reliability 
434 (Peterson \& Kim, 2013). In this sense, as Raykov (2001) comments, the modeling of structural 435 equations has the ability to empirically assess and overcome some of the limitations of the alpha coefficient. The CR results were optimal in the subscales Quality of bonding (mothers, .74;

437 fathers, .80), Absence of hostility (mothers, .93; fathers, .94) and Pleasure in interaction 438 (mothers, .83; fathers, .90). Therefore, the CR results indicate that the reliability of the different 439 subscales is adequate. We considered it necessary to maintain both procedures, coefficient alpha 440 and $\mathrm{CR}$, to allow comparing the results with previous studies and provide all necessary data for 441 future research regarding the scale's reliability.

442 With regard to the scale invariance analyses carried out, we confirmed configural variance, which indicates that the construct was conceptualized in the same way in both samples (Cheung

444 \& Rensvold, 2002); that is, we concluded that mothers and fathers shared the same definition of 445 bonding. We also observed metric invariance, which indicates that the participating mothers 446 probably interpret each item that makes up the scale in the same way as the fathers do. However, 447 it was not possible to confirm complete or partial scalar invariance between these two groups. 448 The lack of invariance in this model may be due to the difference in the sample size of each 449 group, as the size of the group of mothers was twice as large as that of the fathers. As a result, 450 the strict invariance hypothesis is not supported.

451 Concurrent validity, measured through postnatal depression and the quality of the couple's 452 relationship, constructs used in the original PPAS (Condon, Corkindale \& Boyce, 2008), showed 453 high associations in the same line of the scientific literature and were consistent with the 454 hypotheses proposed in the study. These results support the validity of the scale.

\section{Limitations and suggestions for future research}


456 There were several limitations to this study. Firstly, the study data were obtained through self-

457 administered questionnaires, which can lead to response bias such as social desirability. To

458 reduce this bias, the combined use of self-reported questionnaires was suggested along with other

459 types of measures to evaluate the postnatal bond, such as clinical interviews (e.g. The Stafford

460 Interview, Brockington et al., 2017; YIPTA, Leckman et al., 1994) and direct observations (e.g.

461 CIB, Feldman, 1998, BMIS, Kumar \& Hipwell, 1996). In this sense, we consider the need to

462 carry out more in-depth research on the relationship between social desirability and postnatal

463 bonding, as well as related variables. Secondly, the participation of fathers and mothers was

464 unequal and the response rate was low. There are usual limitations associated with studies in this

465 field, but they remain relevant. Thirdly, the homogeneity of the sample characteristics did not

466 allow generalising the results. It would be interesting to use more heterogeneous samples in

467 terms of age, educational level, income, nationality, family structure, context, and associated

468 problems. Additionally, it would be desirable to test the instrument's performance at different

469 stages of the child's life or following interventions, so as to assess the instrument's sensitivity to

470 change.

471 We recommend two future lines of research. On the one hand, a theoretical reflection on the

472 concept of postnatal bonding due to: (a) epistemological inconsistencies found in the review of

473 scientific literature; (b) inconsistencies related to the factor structure of instruments assessing this

474 concept; and (c) the need for further understanding the relationship between gender differences

475 and postnatal bonding, as well as the analysis of the construct considering sociodemographic and

476 cultural variables. On the other hand, as a result of the above, we recommend continuing to study

477 the application of the new scale, including the removed items that belonged exclusively to the

478 mother's or father's scale, or adding new items deriving from further theoretical reflection. This 
479 way, a more relevant and complete construct can be obtained thus contributing to increasing the

480 reliability of the scale.

\section{5. CONCLUSIONS}

482 The new version of the scale of postnatal bonding, showing appropriate structural and concurrent 483 validity and moderate reliability, is suitable for use in mothers and fathers. It evaluates the 484 postnatal bond and allows comparing that of mothers and fathers: this contributes to progressing 485 in perinatal mental health and in understanding gender differences in postnatal bonding. In this 486 regard, we emphasize the need to include fathers in assessment and intervention programs within 487 the context of transition to parenthood, thus favoring a systemic perspective on the family. 488 ACKNOWLEDGEMENTS

489 The authors thank Alejandro Cerezo Munuera for his collaboration in the translating process of 490 the scale, to the institution and all the professionals who participated, as well as to all the couples 491 who contributed to the study.

492

493 494

495 496

497 498

499 500

\section{REFERENCES}

Altaweli R, Roberts J. 2010. Maternal-infant bonding: A concept analysis. British Journal of Midwifery, 18: 552-559. DOI: 10.12968/bjom.2010.18.9.78062

Arbuckle JL. 2014. IBM SPSS Amos 23 user's guide. Crawfordville, FL: Amos Development Corporation.

Belsky J, Fearon RM. 2002. Early attachment security, subsequent maternal sensitivity, and later child development: Does continuity in development depend upon continuity of caregiving? Attachment \& Human Development, 4(3): 361-387. DOI: $10.1080 / 14616730210167267$ 
501 Bicking Kinsey C, Hupcey JE. 2013. State of the science of maternal-infant bonding: A principle502 based concept analysis. Midwifery, 29: 1314-1320. DOI: 10.1016/j.midw.2012.12.019

503 Bowlby J. 1969. Attachment and loss. Vol.1: Attachment. New York: Basic Books [Spanish 504 translation: El apego y la pérdida. Vol.1: El apego. Barcelona: Paidós, 1969].

505 Brockington IF. 2004. Diagnosis and management of post-partum disorders: A review. World 506 Psychiatry, 3(2): 89-95.

507

508

509

510

511

512

513

514

515

516

517

518

519

Brockington IF. 2011. Maternal rejection of the young child: Present status of the clinical syndrome. Psychopathology, 44: 329-336. DOI: 10.1159/000325058

Brockington IF, Fraser C, Wilson D. 2006. The Postpartum Bonding Questionnaire: A validation. Archives of Women's Mental Health, 9: 233-242. DOI: 10.1007/s00737-006-0132-1

Brockington IF, Oates J, George S, Turner D, Vostanis P, Sullivan M, Loh C, Murdoch C. 2001. A screening questionnaire for mother-infant bonding disorders. Archives of Women's Mental Health, 3: 133-140. DOI: 10.1007/s007370170010

Brockington IF, Chandra P, Bramante A, Dubow H, Fakher W, Garcia-Esteve L, Hofberg K, Moussa S, Palacios-Hernández B, Parffit Y, Shieh PL. 2017. The Stafford Interview A comprehensive interview for mother-infant psychiatry. Archives of Women's Mental Health, 20: 107-112. Doi:10.1007/s00737-016-0683-8

Campo-Arias A, Oviedo HC. 2008. Psychometric properties of a scale: internal consistency. Revista de Salud Pública, 10(5): 831-839. DOI: 10.1590/S0124-00642008000500015 
520 Cheung GW, Rensvold RB. 2002. Evaluating goodness-of-fit indexes for testing measurement

521

522

523 Condon JT. 1993. The assessment of antenatal emotional attachment: Development of a 524

525

526

527

528

529

530

531

532

533

534

535

536

537

538

539

540

invariance. Structural Equation Modeling: A Multidisciplinary Journal, 9(2): 233-255. DOI: :10.1207/ S15328007SEM0902_5

questionnaire instrument. British Journal of Medical Psychology, 66: 167-183. DOI: 10.1111/j.2044-8341.1993.tb01739.x

Condon JT. 2015. Maternal Postnatal Attachment Scale [Measurement instrument] Retrieved from: http://hdl.handle.net/2328/35291

Condon JT, Corkindale CJ. 1998. The assessment of parent-to-infant attachment: Development of a self-report questionnaire instrument. Journal of Reproductive and Infant Psychology, 16: 57-76. DOI: 10.1080/02646839808404558

Condon JT, Corkindale CJ, Boyce P. 2008. Assessment of postnatal paternal-infant attachment: Development of a questionnaire instrument. Journal of Reproductive and Infant Psychology, 26(3): 195-210. DOI: 10.1080/02646830701691335

Cox JL, Holden JM, Sagovsky R. 1987. Detection of postnatal depression. Development of the 10-item Edinburgh Postnatal Depression Scale. British Journal of Psychiatry, 150: 782786. DOI: 10.1192/bjp.150.6.782

De Cock ESA, Henrichs J, Klimstra TA, Maas AJBM, Vreeswijk CMJM, Meeus WHJ, van Bakel HJA. 2017. Longitudinal associations between parental bonding, parenting stress, and executive functioning in toddlerhood. Journal of Child and Family Studies, 26 (6): 1723-1733. DOI: $10.1007 / \mathrm{s} 10826-017-0679-7$ 
541 De Cock ESA, Henrichs J, Vreeswijk CMJM, Maas AJBM, Rijk CHAM, van Bakel HJA. 2016. 542 Continuous feelings of love? The parental bond from pregnancy to toddlerhood. Journal of Family Psychology, 30: 125-134. DOI: 10.1037/fam0000138

544 Domínguez-Lara SAD, Merino-Soto CM. 2015. ¿Por qué es importante reportar los intervalos de confianza del coeficiente alfa de Cronbach? Revista Latinoamericana de Ciencias Sociales, Niñez y Juventud, 13(2):1326-1328.

547

548

549

550

551

552

553

554

555

\section{6}

557

558

559

560

561

Edhborg M, Matthiesen AS, Lundh W, Widström AM. 2005. Some early indicators for depressive symptoms and bonding 2 months postpartum-A study of new mothers and fathers. Archives of Women's Mental Health, 8(4): 221-231. DOI: 10.1007/s00737-0050097-5

Feldman R. 1998. Mother-newborn coding system manual. Tel Aviv, Israel: Bar-Ilan University University Press.

Feldman R. 2007. Parent-infant synchrony and the construction of shared timing; Physiological precursors, developmental outcomes, and risk conditions. Journal of Child Psychology and Psychiatry, 48: 329-354. DOI: 10.1111/j.1469-7610.2006.01701.x

Feldstein S, Hane AA, Morrison BM, Huang K-Y. 2004. Relation of the Postnatal Attachment Questionnaire to the Attachment Q-Set. Journal of Reproductive and Infant Psychology, 22(2): 111-121. DOI: 10.1080/0264683042000205972

Figueiredo B, Costa R, Pacheco A, Pais A. 2009. Mother-to-infant Emotional Involvement at Birth. Maternal and Child Health Journal, 13: 539-549. DOI: 10.1007/s10995-008-0312$\mathrm{X}$ 
562 Garcia-Esteve L, Ascaso C, Ojuel J, Navarro P. 2003. Validation of the Edinburgh Postnatal 563 Depression Scale (EPDS) in Spanish mothers. Journal of Affective Disorder, 75: 71-76. 564 DOI: $10.1016 / \mathrm{S} 0165-0327(02) 00020-4$

565 Gartzia L, Aritzeta A, Balluerka N, Barberá E. 2012. Inteligencia emocional y género: más allá 566 de las diferencias sexuales [Emotional intelligence and gender: Beyond sexual 567 differences]. Anales de Psicología, 28(2): 567-575. DOI: 10.6018/analesps.28.2.124111

568 569

570

571

572

573

574 575

576

577

578 579

580

581

582

583

George D, Mallery M. 2010. SPSS for Windows Step by Step: A Simple Guide and Reference, 17.0 update (10a ed.). Boston: Pearson.

Ghadery-Sefat A, Abdeyazdan Z, Badiee Z, Zargham-Boroujeni A. 2016. Relationship between parent-infant attachment and parental satisfaction with supportive nursing care. Iranian Journal of Nursing and Midwifery Research, 21(1): 71-76. DOI: 10.4103/17359066.174756

Güleç D, Kavlak O. 2013. The study of reliability and validity of paternal-infant attachment scale in Turkish society. International Journal of Human Science, 10(2): 170-181.

Hair J, Black B, Babin B, Anderson R, Tatham R. 2006. Multivariate data analysis (6th ed.). Upper Saddle River, NJ: Prentice-Hall.

Hairston IS, Waxler E, Seng JS, Fezzey AG, Rosenblum KL, Muzik M. 2011. The role of infant sleep in intergenerational transmission of trauma. SLEEP, 34(10): 1373-1383. DOI: 10.5665/SLEEP. 1282

Hall RAS, Hoffenkamp HN, Tooten A, Braeken J, Vingerhoets AJJM, Van Bakel HJA. 2015. Child-rearing history and emotional bonding in parents of preterm and full-term infants. Journal of Child Family Studies, 24(6): 1715-1726. DOI: 10.1007/s10826-014-9975-7 
584 Hornstein C, Trautmann-Villalba P, Hohm E, Rave E, Wormann-Fleischer S, Schwarz M. 2006.

585

586

587

588

589

590

591

592

593

594

595

596

597

598

599

600

601

602

603

604
Maternal bond and mother-child interaction in severe postpartum psychiatric disorders: Is there a link? Archive of Women's Mental Health, 9: 279-284. DOI: 10.1007/s00737-0060148-6

Kennell J, McGrath S. 2005. Starting the process of mother-infant bonding. Acta Paediatrica, 94(6): 775-777. DOI: 10.1111/j.1651-2227.2005.tb01982.x

Kumar R, Hipwell AE. 1996. Development of a clinical rating scale to assess mother-infant interaction in a psychiatric mother and baby unit. The British Journal of Psychiatry, 169(1): 18-26. DOI: 10.1192/bjp.169.1.18.

Landeta J. 1999. El método Delphi. Una técnica de previsión para la incertidumbre [The Delphi method. A forecast technique for uncertainty]. Barcelona: Editorial Ariel.

Leckman JF, Mayes L, Feldman R, Evans D, Cohen DJ. 1994. The Yale Inventory of Parent Thoughts and Actions. Edit. Yale University. New Haven, USA.

Little TD. 1997. Mean and covariance structures (MACS) analyses of cross-cultural data: Practical and theoretical issues. Multivariate Behavioral Research, 32(1): 53-76. DOI: $10.1207 / \mathrm{s} 15327906 \mathrm{mbr} 3201 \_3$

Lozano L, García-Cueto E, Muñiz J. 2008. Effect of the number of response categories on the reliability and validity of rating scales. Methodology, 4(2):73- 79. DOI: 10.1027/16142241.4.2.73

Maroto G, García MM, Fernández A. 2005. Evaluación del estado de ánimo en el puerperio con la Escala de Depresión Postnatal de Edimburgo [Assessment of mood in the postnatal 
605

606

607

608

609

610

611

612

613

614

615

616

617

618

619

620

621

622

623

624

period with the Edinburgh Postnatal Depression Scale]. International Journal of Clinical and Health Psychology, 5(2): 305-318.

Mason ZS, Briggs RD, Silver EJ. 2011. Maternal attachment feelings mediate between maternal reports of depression, infant social-emotional development, and parenting stress. Journal of Reproductive and Infant Psychology, 29(4): 382-394. DOI: $10.1080 / 02646838.2011 .629994$

Müller ME. 1994. A questionnaire to measure mother-to-infant attachment. Journal of Nursing Measurement, 2: 129-141.

Nunes O, Pires M, Brites R, Hipólito J, Vasconcelos M, Spitz E. 2014. Maternal Post-Attachment Scale (MPAS): Validation studies to the Portuguese population. Bulletin of the European Health Psychology Society, 16.

Peterson RA, Kim Y. 2013. On relationship Between Coefficient Alpha and Composite Reliability. Journal of Applied Psychology, 98(1): 194-198. DOI: 10.1037/a0030767

Pires M, Nunes O, Brites R, Hipólito J, Vasconcelos M, Spitz E. 2014. Paternal Post-Attachment Scale: Validation studies to the Portuguese population. Bulletin of the European Health Psychology Society, 16.

Ramchandani PG, Domoney J, Sethna V, Psychogiou L, Vlachos H, Murray L. 2013. Do early father-infant interactions predict the onset of externalising behaviours in young children? Findings from a longitudinal cohort study. Journal of Child Psychology and Psychiatry, 54: 56-64. DOI: 10.1111/j.1469-7610.2012.02583.x 
625 Raykov T. 2001. Bias of coefficient $\alpha$ for fixed congeneric measures with correlated errors. 626 Applied Psychological Measurement, 21: 69-76. DOI: 10.1177/01466216010251005

627

628

629

630

631

632

633

634

635

636

637

638

639

640

641

642

643

644

645 Journal of Community Medicine and Public Health, 4(4): 1324-1331. DOI: 10.18203/2394-6040.ijcmph20171370

Santos-Iglesias P, Vallejo-Medina P, Sierra JC. 2009. Propiedades psicométricas de una versión breve de la Escala de Ajuste Diádico en muestras españolas [Psychometric properties of a brief version of the Dyadic Adjustment Scale in Spanish samples]. International Journal of Clinical and Health Psychology, 9(3): 501-517.

Sarkadi A, Kristiansson R, Oberklaid F, Bremberg S. 2008. Fathers' involvement and children's developmental outcomes: A systematic review of longitudinal studies. Acta Paediatrica, 97(2): 153-158. DOI: 10.1111/j.1651-2227.2007.00572.x

Scism AR, Cobb RL. 2017. Integrative review of factors and interventions that influence early father-infant bonding. Journal of Obstetric, Gynecologic \& Neonatal Nursing, 46(2): $163-$ 170. DOI: $10.1016 /$ j.jogn.2016.09.004

Scopesi A, Viterbori P, Sonza S, Zucchinetti P. 2004. Assessing mother-to-infant attachment: The Italian adaptation of a self-report questionnaire. Journal of Reproductive and Infant Psychology, 22(2), 99-109. doi:10.1080/0264683042000205963

Siddiqui A, Hägglöf B. 2000. Does maternal prenatal attachment predict postnatal mother-infant interaction? Early Human Development, 59: 13-25. DOI: 10.1016/S0378-3782(00)00076- 
646 Spanier GB. 1976. Measuring dyadic adjustment: New scales for assessing the quality of 647 marriage and similar dyads. Journal of Marriage and the Family, 38: 15-28. DOI:

648 $10.2307 / 350547$

649

650

651

652

653

654

655

656

657

658

Taylor A, Atkins R, Kumar R, Adams D, Glover V. 2005. Mother-to-infant bonding scale: Links with early maternal mood. Archives of Women's Mental Health, 8(1): 45-51. DOI: $10.1007 / \mathrm{s} 00737-005-0074-\mathrm{z}$

van Bussel JC, Spitz B, Demyttenaere K. 2010. Three self-report questionnaires of the early mother-to-infant bond: Reliability and validity of the Dutch version of the MPAS, PBQ and MIBS. Archives of Women's Mental Health, 13: 373-384. DOI: 10.1007/s00737-009$0140-\mathrm{z}$

Wu LM, Chin CC, Chen CH, Lai FC, Tseng YY. 2011. Development and validation of the Paediatric Cancer Coping Scale. Journal of Advanced Nursing, 67(5): 1142-1151. DOI: 10.1111/j.1365-2648.2010.05567.x 


\section{Figure 1 (on next page)}

Flow chart of the study. 


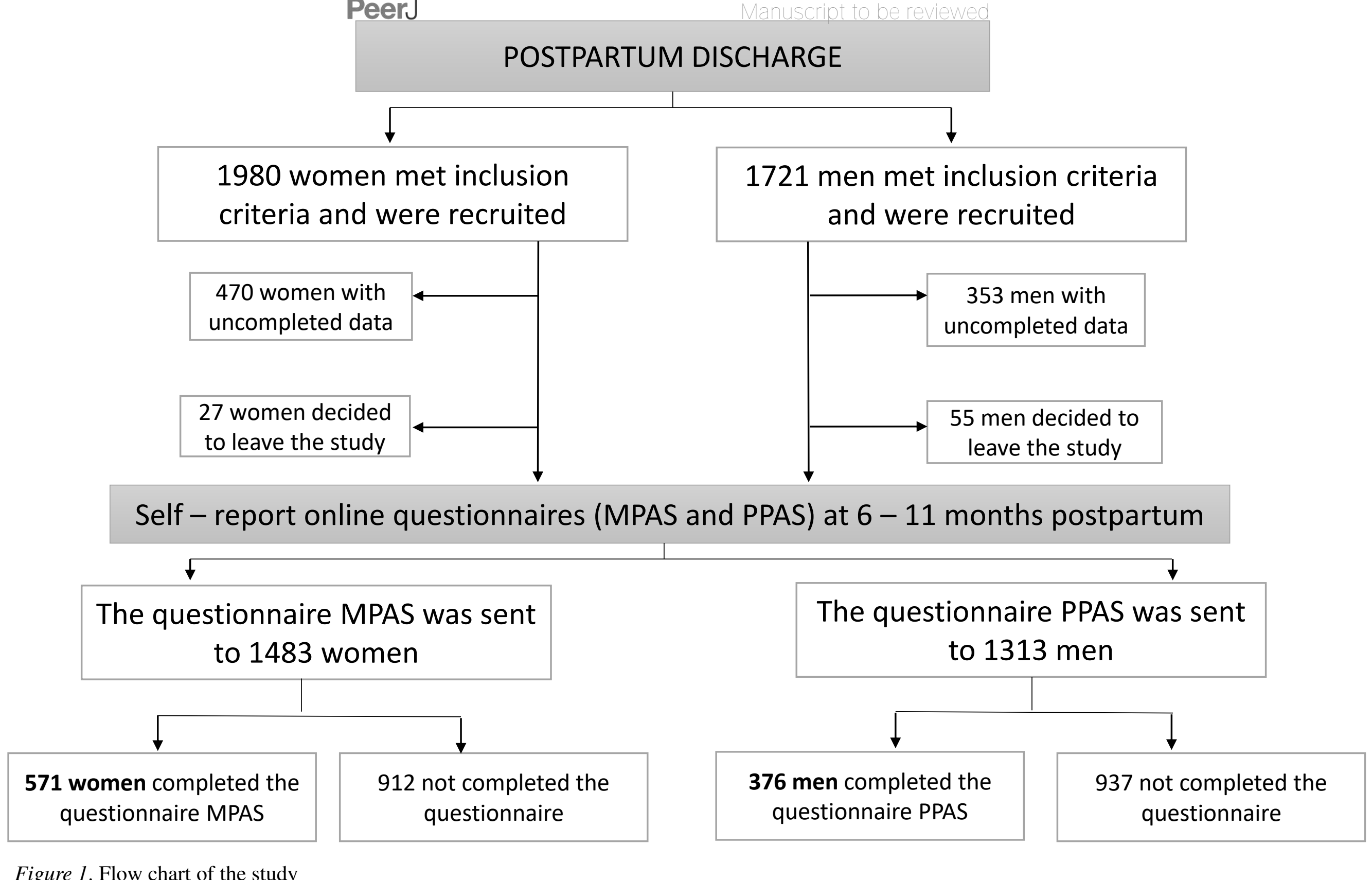

Figure 1. Flow chart of the study 
Figure 2 (on next page)

Factor analysis of PBS by including MPAS items. 


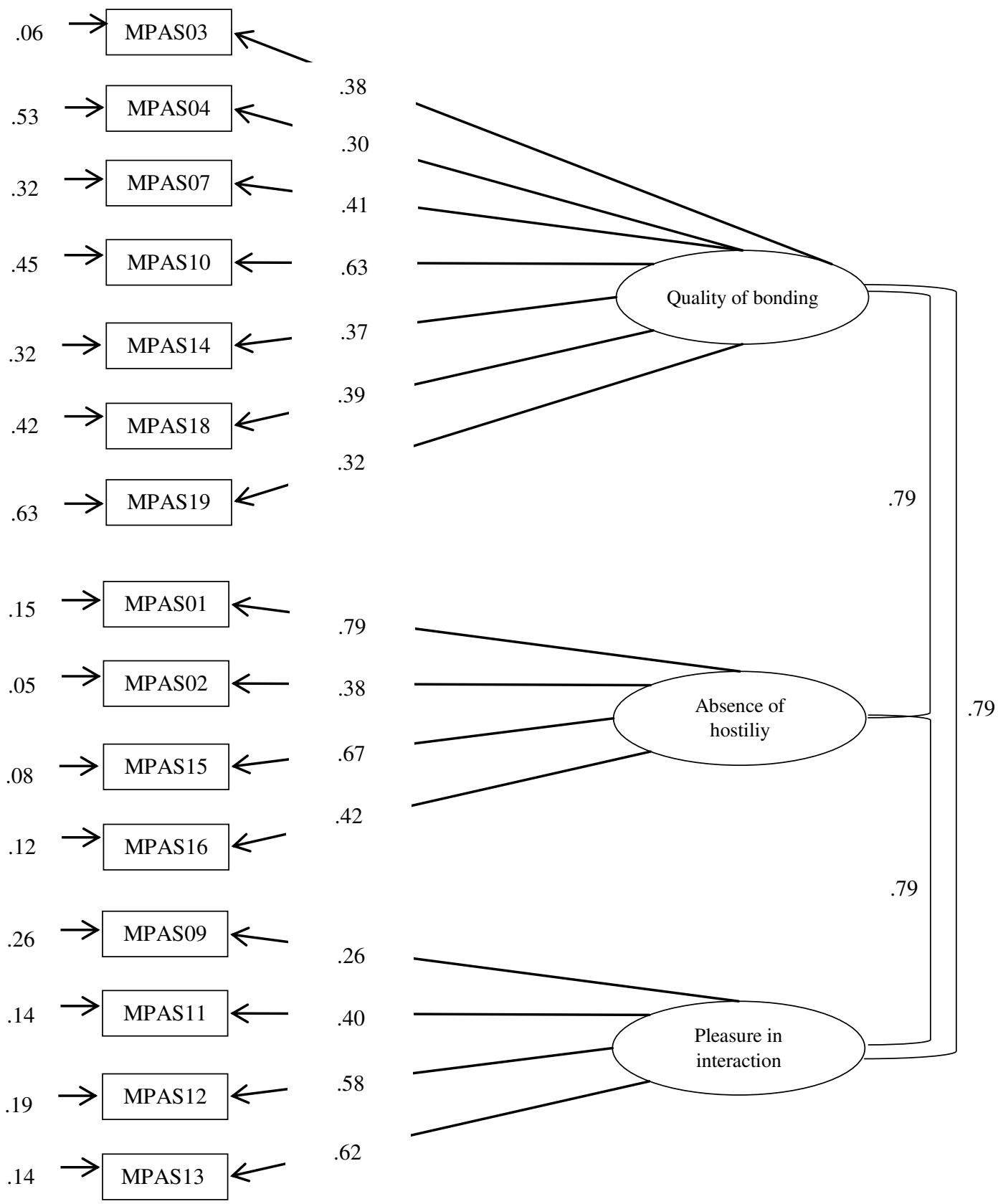

Figure 2. Factor analysis of PBS by including MPAS items 
Figure 3 (on next page)

Factor analysis of PBS by including PPAS items. 

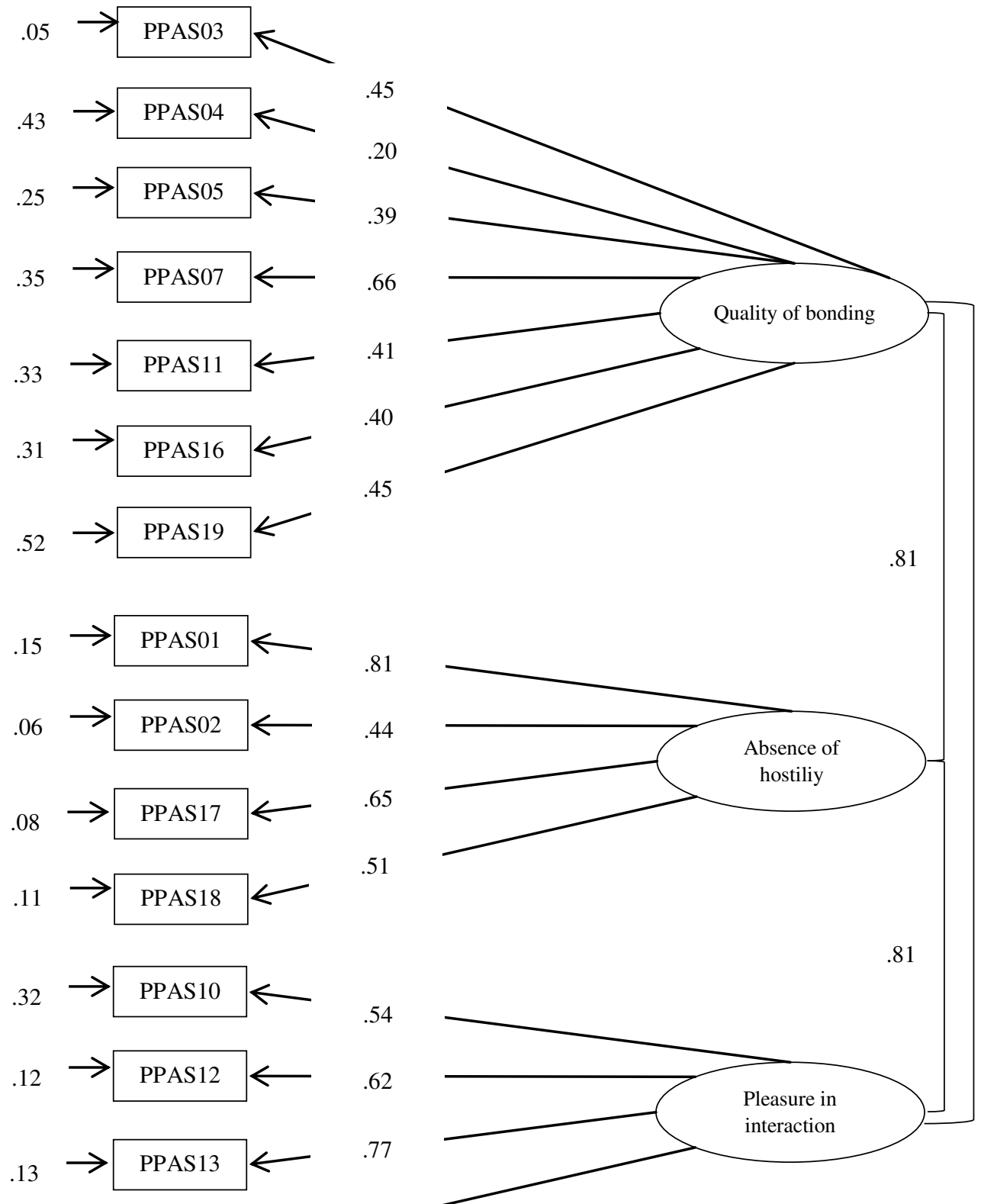

.81

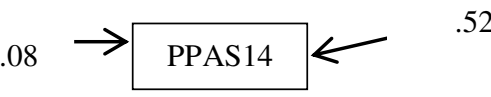

Figure 3. Factor analysis of PBS by including PPAS items 


\section{Table 1 (on next page)}

Characteristics of the study sample $(n=947)$.

Note. $\mathrm{SD}=$ Standard Deviation 
Table 1

2 Characteristics of the study sample $(n=947)$.

\begin{tabular}{|c|c|c|}
\hline & $\begin{array}{c}\text { Mothers } \\
(\mathrm{n}=571)\end{array}$ & $\begin{array}{l}\text { Fathers } \\
(\mathrm{n}=376)\end{array}$ \\
\hline & Mean $\neq$ SD(min-max) & Mean $\neq$ SD(min-max) \\
\hline \multirow[t]{2}{*}{ Age } & $34.13 \neq 4.26(20-47)$ & $35.98 \neq 4.34(23-51)$ \\
\hline & $\mathrm{n}(\%)$ & $\mathrm{n}(\%)$ \\
\hline \multicolumn{3}{|l|}{ Marital Status } \\
\hline Single & $89(15.6)$ & $39(10.4)$ \\
\hline Married & $400(70.1)$ & $253(67.3)$ \\
\hline Separated or Divorced & $12(2.1)$ & $7(1.9)$ \\
\hline Widow & $2(0.5)$ & $0(0)$ \\
\hline Missing Values & $67(11.7)$ & $77(20.5)$ \\
\hline \multicolumn{3}{|l|}{ Coexistence with the partner } \\
\hline Yes & $485(84.9)$ & $292(77.7)$ \\
\hline Some days of the month & $9(1.6)$ & $7(1.9)$ \\
\hline No & $9(1.6)$ & $0(0)$ \\
\hline Missing Values & $68(11.9)$ & $77(20.5)$ \\
\hline \multicolumn{3}{|l|}{ Education } \\
\hline Elementary school or lower & $16(3.8)$ & $22(5.9)$ \\
\hline High School & $96(16.8)$ & $85(22.6)$ \\
\hline High School senior or Vocational Training & $109(19.1)$ & $60(16.0)$ \\
\hline University & $279(48.8)$ & $131(34.9)$ \\
\hline Missing Values & $65(11.4)$ & $78(20.7)$ \\
\hline \multicolumn{3}{|l|}{ Income level } \\
\hline Less than 6000 & $30(5.3)$ & $14(3.7)$ \\
\hline $6000-8999$ & $26(4.6)$ & $8(2.1)$ \\
\hline $9000-11999$ & $51(8.9)$ & $15(4.0)$ \\
\hline 12000-17999 & $108(18.9)$ & $58(15.4)$ \\
\hline 18000-29999 & $142(24.9)$ & $100(26.6)$ \\
\hline $30000-44999$ & $81(14.2)$ & $61(16.2)$ \\
\hline $45000-60000$ & $33(5.8)$ & $27(7.2)$ \\
\hline More than 60000 & $18(3.2)$ & $12(3.2)$ \\
\hline Missing Values & $82(14.4)$ & $81(21.5)$ \\
\hline \multicolumn{3}{|l|}{ Nationality } \\
\hline Spanish & $524(91.8)$ & $292(77.7)$ \\
\hline Other & $25(4.4)$ & $14(3.7)$ \\
\hline Missing Values & $22(3.9)$ & $70(18.6)$ \\
\hline
\end{tabular}




\section{Table 2 (on next page)}

Item distribution and descriptive characteristics of MPAS.

Note. $1-5=$ Number of response options; $M=$ Mean; $S D=$ Standard Deviation; $S=$ Skewness index; $\mathrm{Ku}=$ Kurtosis index; $r^{\circ}=$ item-subscale correlation; $\alpha$ - item ${ }^{\circ}=$ reliability index of the subscale if the item is removed; $r=$ item-global scale correlation; $\alpha$ - item $=$ reliability index of the global scale if the item is removed. 
1 Table 2

2 Item distribution and descriptive characteristics of MPAS.

\begin{tabular}{lccccccccccccc}
\hline & 1 & 2 & 3 & 4 & 5 & $\mathrm{M}$ & $\mathrm{SD}$ & $\mathrm{S}$ & $\mathrm{Ku}$ & $\mathrm{r}$ & $\begin{array}{c}\alpha- \\
\text { item }\end{array}$ & $\begin{array}{c}\mathrm{r} \\
\text { item }\end{array}$ \\
\hline MPAS03 & 0 & 0.2 & 0 & 4.0 & 95.8 & 4.95 & .232 & -6.42 & 55.1 & .282 & .619 & .289 & .747 \\
MPAS04 & 1.2 & 1.7 & 5.9 & 16.0 & 75.1 & 4.61 & .778 & -2.43 & 6.26 & .296 & .609 & .284 & .744 \\
MPAS05 & 0.3 & 1.6 & 4.9 & 32.1 & 61.1 & 4.52 & .696 & -1.65 & 3.41 & .420 & .570 & .382 & .736 \\
MPAS06 & 0.2 & 0.5 & 9.4 & 41.5 & 48.4 & 4.37 & .690 & -.872 & .611 & .407 & .574 & .480 & .728 \\
MPAS07 & 0.2 & 0.2 & 0.7 & 11.8 & 87.1 & 4.86 & .411 & -3.70 & 19.8 & .291 & .609 & .298 & .744 \\
MPAS10 & 0.2 & 0 & 0.9 & 18.8 & 80.1 & 4.79 & .454 & -2.46 & 9.41 & .433 & .581 & .508 & .732 \\
MPAS14 & 0 & 0 & 1.7 & 14.8 & 83.4 & 4.82 & .430 & -2.28 & 4.61 & .215 & .621 & .246 & .746 \\
MPAS18 & 0 & 0.3 & 1.9 & 44.8 & 53.0 & 4.50 & .5557 & -.654 & .104 & .346 & .593 & .295 & .743 \\
MPAS19 & 1.6 & 3.3 & 13.9 & 34.0 & 47.2 & 4.22 & .916 & -1.20 & 1.26 & .273 & .629 & .299 & .744 \\
\hline MPAS01 & 0 & 0.7 & 8.4 & 42.0 & 49.0 & 4.39 & .669 & -.791 & .103 & .422 & .464 & .565 & .721 \\
MPAS02 & 0 & 0 & 2.4 & 13.8 & 83.8 & 4.81 & .448 & -2.93 & 5.15 & .231 & .555 & .276 & .744 \\
MPAS15 & 0 & 0.7 & 6.4 & 18.6 & 74.2 & 4.66 & .628 & -1.85 & 2.77 & .291 & .525 & .434 & .732 \\
MPAS16 & 15.9 & 20.4 & 34.8 & 23.7 & 5.2 & 2.82 & 1.12 & -.098 & -.78 & .471 & .398 & .364 & .740 \\
MPAS17 & 47.0 & 29.6 & 12.5 & 5.9 & 4.9 & 1.92 & 1.13 & 1.23 & .769 & .296 & .544 & .204 & .760 \\
\hline MPAS08 & 0 & 0 & 2.6 & 28.9 & 68.5 & 4.66 & .527 & -1.20 & .418 & .289 & .596 & .475 & .732 \\
MPAS09 & 2.3 & 11.7 & 26.8 & 31.2 & 28.0 & 3.71 & 1.07 & -.434 & -.62 & .420 & .581 & .196 & .759 \\
MPAS11 & 0 & 3.3 & 0 & 16.4 & 80.3 & 4.74 & .627 & -2.97 & 9.49 & .421 & .535 & .246 & .746 \\
MPAS12 & 0.2 & 0.5 & 6.3 & 39.0 & 54.0 & 4.46 & .653 & -1.08 & 1.38 & .487 & .499 & .464 & .730 \\
MPAS13 & 0 & 0.3 & 0.5 & 11.7 & 87.5 & 4.86 & .388 & -3.24 & 13.2 & .376 & .579 & .392 & .740 \\
\hline & & & $\alpha=.75 ; \mathrm{KMO}=.833$, Bartlett's Sphericity Test $1990,44, p<.001$ & &
\end{tabular}

$\alpha=.75 ; \mathrm{KMO}=.833$, Bartlett's Sphericity Test $1990,44, p<.001$

\footnotetext{
Note. $1-5=$ Number of response options; $\mathrm{M}=$ Mean; $\mathrm{SD}=$ Standard Deviation; $\mathrm{S}=$ Skewness index; Ku $=\mathrm{Kurtosis}$ index; $\mathrm{r}^{\circ}=$ item-subscale
4 correlation; $\alpha-$ item $^{\circ}=$ reliability index of the subscale if the item is removed; $\mathrm{r}=$ item-global scale correlation; $\alpha-$ item $=$ reliability index of the global scale if the item is removed.
} 


\section{Table 3(on next page)}

Item distribution and descriptive characteristics of PPAS.

Note. $1-5=$ Number of response options; $\mathrm{M}=$ Mean; $\mathrm{SD}=$ Standard Deviation; $\mathrm{S}=$ SkewnesS index; $\mathrm{Ku}=$ Kurtosis index; $r^{\circ}=$ item-subscale correlation; $\alpha$ - item ${ }^{\circ}=$ reliability index of the subscale if the item is removed; $r=$ item-global scale correlation; $\alpha$ - item = reliability index of the global scale if the item is removed. 
1 Table 3

2 Item distribution and descriptive characteristics of PPAS.

\begin{tabular}{lccccccccccccc}
\hline & 1 & 2 & 3 & 4 & 5 & $\mathrm{M}$ & $\mathrm{SD}$ & $\mathrm{S}$ & $\mathrm{Ku}$ & $\mathrm{r}^{\circ}$ & $\alpha-$ & $\mathrm{r}$ & $\begin{array}{c}\alpha- \\
\text { ítem }\end{array}$ \\
\hline PPAS01 & 0.3 & 1.3 & 21.1 & 43.5 & 33.8 & 4.09 & .786 & -.460 & -.29 & .642 & .733 & .564 & .817 \\
PPAS02 & 0 & 0.3 & 4.2 & 19.0 & 76.5 & 4.72 & .551 & -1.93 & 3.24 & .356 & .778 & .340 & .828 \\
PPAS06 & 0.8 & 1.6 & 11.9 & 36.7 & 49.1 & 4.32 & .803 & -1.19 & 1.58 & .631 & .734 & .629 & .813 \\
PPAS11 & 0 & 0.3 & 1.3 & 31.1 & 67.3 & 4.65 & .519 & -1.22 & 1.15 & .552 & .758 & .586 & .820 \\
PPAS13 & 0.5 & 4.2 & 18.2 & 52.2 & 24.8 & 3.97 & .804 & -.674 & .580 & .457 & .764 & .621 & .814 \\
PPAS17 & 0 & 1.3 & 8.2 & 26.9 & 63.6 & 4.53 & .617 & -1.28 & .870 & .505 & .757 & .483 & .822 \\
PPAS18 & 8.4 & 20.6 & 35.6 & 27.4 & 7.9 & 3.06 & 1.07 & -.143 & -.56 & .462 & .772 & .382 & .829 \\
PPAS19 & 1.6 & 4.2 & 17.9 & 37.5 & 38.8 & 4.01 & .935 & -.933 & .603 & .416 & .775 & .388 & .827 \\
\hline PPAS04 & 0 & 0.8 & 10.3 & 67.0 & 21.9 & 4.10 & .587 & -.257 & .827 & .266 & .601 & .345 & .828 \\
PPAS05 & 2.6 & 3.2 & 9.2 & 32.7 & 52.2 & 4.29 & .948 & -1.58 & 1.57 & .107 & .660 & .154 & .841 \\
PPAS08 & 0.3 & 1.1 & 6.1 & 40.1 & 52.5 & 4.44 & .681 & -1.21 & 2.02 & .413 & .561 & .494 & .821 \\
PPAS09 & 0 & 2.6 & 25.9 & 47.2 & 24.3 & 3.93 & .777 & -.221 & -.57 & .382 & .565 & .359 & .828 \\
PPAS10 & 7.7 & 17.4 & 39.1 & 21.4 & 14.5 & 3.18 & 1.12 & -.055 & -.56 & .324 & .592 & .409 & .828 \\
PPAS12 & 0 & 7.4 & 32.5 & 39.8 & 20.3 & 3.73 & .868 & -.134 & -.71 & .483 & .526 & .493 & .821 \\
PPAS15 & 0.3 & 2.6 & 17.7 & 44.3 & 35.1 & 4.11 & .804 & -.639 & .061 & .444 & .544 & .475 & .822 \\
\hline PPAS03 & 0 & 0 & 0.3 & 9.0 & 90.8 & 4.91 & .302 & -3.06 & 8.54 & .397 & .528 & .404 & .829 \\
PPAS07 & 0.3 & 0 & 1.1 & 18.2 & 80.5 & 4.79 & .471 & -2.75 & 11.9 & .371 & .507 & .325 & .829 \\
PPAS14 & 0.3 & 0.3 & 2.6 & 26.6 & 70.2 & 4.66 & .567 & -1.91 & 5.37 & .369 & .511 & .428 & .825 \\
PPAS16 & 0 & 0.3 & 6.1 & 28.5 & 65.2 & 4.59 & .617 & -1.28 & .870 & .398 & .492 & .345 & .828 \\
\hline
\end{tabular}

$\alpha=.83 ; \mathrm{KMO}=.882$, Bartlett's test of sphericity $1816,56, p<.001$ 


\section{Table 4 (on next page)}

Confirmatory factor Analyses summary for the MPAS and PPAS.

Note. $\chi 2=$ chi-square; $\mathrm{df}=$ degrees of freedom, $\mathrm{p}=$ probability; GFI = Goodness of fit index; $\mathrm{CFI}=$ Comparative fit index; RMSEA $=$ Root Mean Square Error of Approximation; RMSEA (IC$90 \%)=$ RMSEA confidence interval; $3 \mathrm{~F}=$ Original version of 3 factors; $6 \mathrm{~F}=$ Italian version; $2 \mathrm{~F}$ $14=$ Portugal version; $2 \mathrm{~F}-16=$ Portugal version; $3 \mathrm{~F}-\mathrm{COM}=$ Single version for fathers and mothers with 15 items. 
Table 4

2 Confirmatory factor Analyses summary for the MPAS and PPAS.

\begin{tabular}{|c|c|c|c|c|c|c|c|c|}
\hline & Model & $x^{2}$ & $\mathrm{df}$ & $\mathrm{p}$ & GFI & CFI & RMSEA & $\begin{array}{l}\text { RMSEA } \\
\text { IC- } 90 \%\end{array}$ \\
\hline \multirow{4}{*}{ 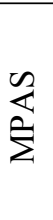 } & $3 \mathrm{~F}$ & 447.893 & 146 & .000 & .92 & .84 & ,060 & $(.054-.066)$ \\
\hline & $6 \mathrm{~F}$ & 457.000 & 137 & .000 & .92 & .83 & .064 & $(.057-.070)$ \\
\hline & $2 \mathrm{~F}-14$ & 315.035 & 76 & .000 & .92 & .79 & .074 & $(.066-.083)$ \\
\hline & 3F-COM & 196.005 & 83 & .000 & .96 & .91 & .049 & $(.040-.058)$ \\
\hline \multirow{3}{*}{$\frac{n}{\Delta}$} & $3 \mathrm{~F}$ & 390.265 & 146 & .000 & .90 & .86 & .067 & $(.059-.075)$ \\
\hline & $2 F-16$ & 282.954 & 103 & .003 & .91 & .87 & .068 & $(.059-.078)$ \\
\hline & $3 \mathrm{~F}-\mathrm{COM}$ & 197.754 & 83 & .000 & .93 & .90 & .060 & $(.049-.071)$ \\
\hline
\end{tabular}

Note. $\chi^{2}$ = chi-square; $\mathrm{df}=$ degrees of freedom, $\mathrm{p}=$ probability; $\mathrm{GFI}=$ Goodness of fit index; $\mathrm{CFI}=$ Comparative fit index; RMSEA = Root Mean Square Error of Approximation; RMSEA (Ic-90\%) $=$ RMSEA confidence interval; $3 \mathrm{~F}=$ Original version of 3 factors; $6 \mathrm{~F}=\mathrm{Italian}$ version; $2 \mathrm{~F}-14=$ Portugal version; $2 \mathrm{~F}-16=$ Portugal version; $3 \mathrm{~F}-\mathrm{COM}=$ Single version for fathers and mothers with 15 items. 


\section{Table 5 (on next page)}

Fit indices for invariance tests.

Note. $\chi 2$ = chi-square; $\mathrm{df}=$ degrees of freedom, $\mathrm{p}=$ probability; $\mathrm{CFI}=$ Comparative fit index; $\Delta \mathrm{CFI}=$ Change of the Comparative fit index; RMSEA $=$ Root Mean Square Error of Approximation; RMSEA (Ic-90\%) = RMSEA confidence interval. 
1 Table 5

$2 \quad$ Fit indices for invariance tests.

\begin{tabular}{lllllll}
\hline$\chi^{2}$ & df & $\mathrm{p}$ & CFI & $\Delta \mathrm{CFI}$ & RMSEA & RMSEA 90\% CI \\
\hline
\end{tabular}

\section{Mothers-Fathers}

$\begin{array}{llllllll}\text { Configural } & 376.634 & 166 & .000 & .905 & - & .037 & (.032-.041) \\ \text { Metric } & 395.052 & 176 & .000 & .901 & .004 & .036 & (.031-.041) \\ \text { Scalar } & 542.416 & 185 & .000 & .838 & .063 & .045 & (.041-.049)\end{array}$

3 Note. $\chi^{2}=$ chi-square; $\mathrm{df}=$ degrees of freedom, $\mathrm{p}=$ probability; $\mathrm{CFI}=$ Comparative fit index; $\Delta \mathrm{CFI}=\mathrm{Change}$ of the Comparative fit 4 index; RMSEA = Root Mean Square Error of Approximation; RMSEA (Ic-90\%) = RMSEA confidence interval. 